\title{
MODELO INDUSTRIAL E MEIO AMBIENTE NO ESPAÇO BRASILEIRO
}

\author{
RUY MOREIRA \\ Universidade Federal Fluminense
}

O quadro ambiental de uma sociedade moderna relaciona-se com o do seu modelo industrial. O Brasil talvez seja um caso típico desta relação estrutural. $\mathrm{O}$ modo do arranjo do espaço do modelo industrial é o pano de fundo que está por traz das incidências dos problemas ambientais brasileiros que a academia e a imprensa retratam diariamente.

Vimos em texto anterior o conceito e o processo evolutivo do modelo industrial brasileiro, seu esgotamento e entrada em fase de reestruturação (MOREIRA, 2002). Retomamo-lo agora, enfocando-o em seus ângulos espaço-ambientais no plano do espaço brasileiro.

O propósito é oferecer subsídios à formação de um quadro de referência para a montagem do painel da relação modelo industrial e meio ambiente na escala macro do Brasil, tarefa cuja premência já passou no tempo.

\section{Referências conceituais}

Uma consideração conceitual é uma preliminar necessária. Vejamos, primeiramente, as categorias do espaço e do meio ambiente e seus entrelaçamentos, mediados pelo território. Em seguida, as categorias da indústria e do espaço. E, então, as do espaço industrial brasileiro, mais propriamente. 


\section{Espaço, território e meio ambiente}

É sabido que todo fenômeno ambiental se dá num ponto definido da superfície terrestre. $O$ espaço é a estrutura do seu contexto, o âmbito constitutivo do seu valor relacional. Todo relacionamento do homem com o seu entorno parte do suposto da escolha seminal da localização, um processo de referência da seletividade que vai dar na construção do habitat, e assim do espaço e do meio ambiente (MOREIRA, 2001). A localização é um procedimento plural, e então a seletividade é distribuição. O fio da unidade da distribuição é a própria relação do encadeamento dos fenômenos, em que ecossistema e habitat se entrelaçam como momentos de um só movimento processual, o de constituição do espaço geográfico, história da natureza e histórica do homem se confundindo numa só (MOREIRA, 1997). Formam-se, assim, os territórios, recortes do arranjo espacial gerados pelos âmbitos de domínios dos lugares seletivos. Múltiplos e entrecruzados, os territórios interagem e integramse numa complexidade estrutural única, que é a escala do espaço geográfico.

Assim interrelacionalmente se definem o espaço, o território e o meio ambiente. $O$ espaço é o contexto geral da totalidade. O território é o recorte espacial do domínio, dito domínio territorial. O meio ambiente é essa complexidade estrutural do espaço territorializado, vista em sua ligação com o paradigma técnico, cujo elo simbólico é o imaginário de relação do homem com a natureza que o acompanha.

A geografia cunhou dois conceitos para teorizar sobre este tema da relação do espaço e do meio ambiente: o gênero de vida e o meio técnico-científico, o primeiro por Vidal La Blache e o segundo recentemente por Santos. Sorre é a mediação de passagem de um para o outro.

\section{A natureza da indústria e o meio ambiente}

Presença da técnica é sinônimo de indústria. A natureza da técnica é a ambientalização da prática territorial do homem. Mais que uma mediação, é a própria objetificação da relação paradigmática do homem com o meio (MOREIRA, 1993). Isto torna possível uma periodização da história ambiental da humanidade em três grandes momentos: do artesanato, da manufatura e da fábrica.

$O$ período do artesanato é marcado por forte relação de pertencimento. $O$ poder técnico do homem, definido pelas ferramentas manuais e a energia muscular, só é suficiente para permitir o manuseio da matéria dútil. Isto é, a matéria vegetal e animal, quando muito o barro, no mundo mineral. O que determina a natureza das matérias-primas. O raio de alcance da distribuição das localizações seletivas pouco vai além da cercania imediata. Sendo assim, há uma identidade ambiental recíproca do homem e dos componentes da natureza, o homem se reconhecendo na história do entorno e a história do entorno na sua. O móvel que tem na sua sala, por exemplo, veio de uma árvore que viu crescer (quando não a plantou) e ele mesmo extraiu e 
transportou da floresta à oficina onde a transformou na madeira e no móvel que tem à frente com o trabalho de suas mãos. Isto leva-o a constituir uma visão de mundo criado à imagem e semelhança sua. Contatado com a natureza viva, vendo que o que sucede com as plantas, os animais e o homem em tudo se assemelha, plantas e animais igualmente nascem, crescem, morrem e renascem como ele, numa continuidade ininterrupta da vida, o homem forma um conceito de natureza como coisa viva. Homem e natureza formandó um só mundô, điferénciado mas sem dicotomias.

Outro é o quadro do período fabril. A própria dimensão da escala da técnica faz a diferença. $O$ poder da técnica é ilimitado na relação do homem de transformação da natureza, dominando desde a matéria dútil à mais resistente a mudanças. Isso determina a fonte mineral como matéria-prima, numa cultura geológica de civilização. A escala das localizações seletivas é ilimitada, sendo o raio de alcance do abarcamento do espaço o planeta. Não há mais assim identidade entre os móveis da sala e a vida do seu proprietário. Fruto de uma divisão técnica e territorial do trabalho que transcende o olhar e a vivência imediata do homem, o sentido do pertencimento transferese para uma forma de espaço vivido que não conta uma mesma história comum entre os homens e as coisas do entorno. Uma enorme relação de estranhamento, só vencível no reencontro do homem consigo mesmo através da consciência do trabalho abstrato, propicia a constituição de uma concepção dicotômica do mundo, à cuja base está a dicotomia que o capital estabelece na sua relação com o trabalho, impondo-a, por decorrência, também na relação entre os homens e os objetos (MOREIRA, 1982). Contatado tecnicamente e em crescendo com uma natureza mineral, num entorno inorgânico (tudo que materialmente o cerca vem da transformação de matérias-primas extraídas do sub-solo), portanto nada vendo em comum entre a reprodução da vida e a reprodução das coisas (que mais parecem formalmente imutáveis e eternas), a alienação homem-objetos do mundo naturaliza-se, a natureza sendo vista como uma coisa física, e o mundo como uma relação dicotômica entre o homem (a vida) e a natureza (a coisa mineral sem vida).

O período da manufatura faz a transição entre o artesanal e o fabril. Responde pelo imaginário que rompe com a visão antropomórfica do mundo do artesanato e lança o homem na relação dicotômica e utilitária de natureza do mundo moderno da fábrica. O processo foi por nós descrito em outro texto (MOREIRA, 1991), por Baudrillard (1972) e Thompson (1978).

\section{O modelo industrial e o meio ambiente}

O modelo industrial faz, pois, o meio. A forma de relação com a natureza externa e o imaginário de natureza e de homem que a impregna têm origem na prática da indústria (MARX, ). À forma histórica de indústria, rural-natural no tempo do artesanato e urbano-tecnológica no tempo da fábrica, corresponde a idéia de meio ambiente das comunidades tradicionais do passado e modernas do presente. Natureza e 
homem sendo conceitos culturalmente definidos, meio ambiente é o que em cada tempo diz o homem do seu entorno (GONÇALVES, 2000)

$O$ modo de relação do homem com o ambiente do entorno (o chamado meio ambiente) está então fortemente vinculado à mediação do arranjo do espaço que o modelo industrial, enquanto modo de produção no tempo, organiza como forma de regulação dos homens em sua relação com o mundo.

É o regime de acumulação que o modelo industrial tem na sua base, aquilo que determina o modo da regulação do espaço, e, então, do todo da relação do homem com o ambiente (MOREIRA, 2002),

Vale verificar esta acertiva na forma como ela se processou no plano históricoconcreto do moderno espaço industrial brasileiro.

Uma palavra rápida, entretanto, sobre nosso entendimento de espaço industrial. Entendemos por espaço industrial a forma moderna de estruturar o desenvolvimento econômico a partir de um espaço relacional que tem a fábrica no centro e os demais setores a ela articulados em rede. Podemos falar de montante e jusante da fábrica, dando-Ihe um poder de organização e modelização dos arranjos do espaço ao infinito que chamamos de centralidade fabril. A referência é George, seu conceito de espaço descontínuo, concentrado, relacional, universal e móvel (GEORGE, s/d), acrescido de parâmetros extraidos das categorias da economia política do espaço, geradas por distintos geógrafos de recorte marxista recentemente.

Espaço de relações, o espaço industrial é por isso um todo a um só tempo diferencial e articulado em rede, ordenado numa lógica de mercado, que, por meio da técni$c a$, se difunde e engravida o meio ambiente profundamente. $O$ regime de acumulação faz a vez de ponto de aglutinação desse todo ao redor da fábrica no seu exercício de centralidade. A formatação matricial do espaço assim estabelecida é a fonte dos rearranjos que amarram a própria maneira como o paradigma técnico, em suas ações, movimenta e (re)organiza o todo do entorno-natureza, transformando-o. Eis resumida a teoria.

\section{O modelo industrial e o modelo de espaço brasileiro}

\section{O modelo industrial brasileiro}

A industrialização deu-se no Brasil na forma da substituição de importações. Um modelo industrial com três características principalmente, considerado o tema ambiental. Primeiramente, desenvolvem-se basicamente os ramos destinados a suprir a demanda da elite e da classe média, vale dizer, da população dotada de renda para consumo no mercado. Em segundo lugar, mobilizam-se capitais em montante capaz de oferecer resposta imediata a uma necessidade de produção em volume até certo ponto esperada, o que faz a indústria acompanhar a estrutura monopolista exis- 
tente, já nascendo fortemente concentrada, em termos de ramos e empresa. Em terceiro, condicionam-se todos os setores existentes a uma forma de vinculação com o ramo-base do regime de acumulação posto a serviço dos lucros oligopólicos, em particular a agropecuária, a energia e a circulação, pré-determinando-os como modelos. Estas três características expressam a lógica do mercado, no modo como aqui se faz presente.

Duas distorções sócioespaciais derivam dessas três principais características. Primeiramente, a evolução industrial brasileira centrar-se-á fundamentalmente no desenvolvimento da indústria de bens de consumo consumidos pela elite e pela classe média, duráveis numa primeira fase, passando rapidamente para os não-duráveis na fase seguinte, desenvolvendo-se os ramos de bens de capital e bens intermediários na medida e nos limites do paradigma do consumo. Em segundo lugar, a estrutura oligopolista reproduz-se na forma da concentração e centralização espacial da indústria, localizando-a quase toda na região Sudeste. Nascida dispersa (CASTRO, 1997), a indústria vai-se concentrando regionalmente, quanto mais a industrialização se acelera (GEIGER, 1963).

Esta arrumação concentrada do modelo do espaço chega às cidades. Estas nascem na forma de grandes concentrações metropolitanas, de administração praticamente impossível, do ponto de vista socioambiental.

Dois regimes de acumulação centram a base deste modelo em dois momentos de tempo: o regime de base alimentar-têxtil, no curso dos anos que vão até os 50, e o regime de base automobilística, vigente dos anos 60 até recentemente. Após os anos 80 a economia brasileira tende a centrar-se na agroindústria, caminhando para tornar-se política de Estado nas futuras décadas (MOREIRA, 2002 e 2003).

Segundo a vigência deste ou daquele regime, podemos falar de um modelo de organização do espaço formatado em duas matrizes, com problemas ambientais correspondentes. Chamaremos a primeira, centrada na indústria alimentar-têxtil, de modelo de grandes espaços. À segunda, centrada na indústria automobilística, de modelo dos grandes projetos.

A matriz de espaço centrada na acumulação automobilística, pelo fosso que se estabelece entre a região desenvolvida e industrial, a região Sudeste, e as demais regiões, com ela envolvida como fornecedoras de força-de-trabalho, a região Nordeste, de alimentos, a região Sul, e de espaços para expansão econômica, as regiões Centro Oeste e Norte, hierarquiza as relações regionais numa divisão interregional de trabalho centrada em São Paulo. Esta divisão territorial do trabalho distingue e separa o centro industrial e as regiões-complemento, organizando todos os fluxos territoriais do capital e do trabalho nestes termos (OLIVEIRA, 1984; SANTOS e SILVEIRA, 2001).

Estamos a caminho, ao que tudo indica, enfatizemos, de uma nova forma de matriz espacial, centrada certamente no complexo agroindustrial, com uma nova divisão territorial de trabalho. Tema de um outro texto (MOREIRA, 2003). 


\section{A matriz espacial dos grandes projetos}

É na vigência do espaço dos grandes projetos que o Brasil vai conhecer seus grandes problemas de meio ambiente.

Por grandes projetos entendemos a política de ocupação e organização do espaço através de investimentos em obras de infraestrutura de ampla escala territorial, implementadas a partir de pontos estrategicamente localizados no espaço nacional (VAINER e ARAÚJO, 1992). Vinculados a um determinado setor - o que significa o abandono da política do planejamento por regiões, própria do modelo dos grandes espaços -, a exemplo de uma usina hidrelétrica ou de uma grande rodovia, os pólos dos grandes projetos são os pontos de uma rede que cobre e articula as áreas do país como partes de um projeto de desenvolvimento nacional global, cujo comando está nos centros de referência do ordenamento do espaço nacional como um todo, particularmente São Paulo e Rio de Janeiro.

Este espaço dos grandes projetos tem origem no próprio modelo histórico de desenvolvimento do Brasil. Nele, se incorpora e dá-se novo sentido aos modos estruturais e de ordenamento territorial que o modelo industrial herda do passado, entrelaçando momentos novos (os pólos setoriais) a momentos antigos (os macro-espaços) de configuração de espaço (MOREIRA, 1981).

Os vetores espaciais da desorganização do meio ambiente

E são portanto os setores, organizados em termos de modelos, ditos modelo agrícola, modelo energético, modelo de circulação, modelo urbano, reprodutivos da lógica intrínseca que preside o modelo industrial no seu todo, os vetores da desarrumação socioambiental do espaço brasileiro.

Vejamos como isto se dá e as tendências futuras de desdrobramento.

\section{O modelo industrial e o meio ambiente no espaço brasileiro}

O espaço-contexto onde os problemas ambientais brasileiros se dão e de onde retiram o seu sentido e valor relativo é o espaço criado pelo modo de desenvolvimento industrial brasileiro, filho da técnica da segunda revolução industrial, por isso de centralidade fabril de um capitalismo avançado, produtor-realizador da mais valia-relativa, e da industrialização substitutiva de importações, com as características estruturais, características que se tornam espaciais, determinando o modelo espacial brasileiro, que vimos. 


\section{O modelo do ramo de bens intermediários}

A indústria de bens intermediários é uma espécie de fio vermelho da degradação do meio ambiente no Brasil, dado o papel a ela reservado pelo modelo industrial na constituição e ordenamento do espaço global brasileiro. Sob certa medida, quando se acusa a indústria de vilão do meio ambiente, é à modelização do setor de bens intermediários pelo modelo do desenvolvimento industrial que a crítica está se referindo.

Chama-se indústria de bens intermediários aos ramos da indústria metalúrgica (incluindo-se a siderurgia), não-metálicos, química, papel e celulose. Ramo presente em cada fase do processo do desenvolvimento industrial brasileiro, a indústria de bens intermediários atua em cada uma como protagonista, jamais formando uma fase própria.

Pode-se estabelecer uma periodização do seu grau de incidência ambiental, dividida em três grandes momentos.

O primeiro momento corresponde à primeira fase da industrialização substitutiva. Relaciona-se aos esforços de implantação de uma indústria metalúrgica, em particular a siderurgia, e de uma indústria de materiais de construção, em particular a indústria de cimento, necessárias de um lado ao desenvolvimento da exportação de bens agropecuários, requerente em um suporte de metalurgia à indústria de beneficiamento dos produtos exportados, o que justifica a insistência na criação dạ metalurgia, e de outro ao desenvolvimento das cidades e do sistema rodoviário em crescimento, justificando a insistência na indústria do aço e do cimento. Há desmatamento e assoreamento pontuais, por conta da mineração e do consumo de lenha como fontes de matéria-prima e de energia desmandados por essas indústrias. Mas não há visibilidade ainda nos efeitos ambientais, dado os limites da escala técnica desse primeiro momento.

O segundo momento corresponde à segunda e terceira fases da industrialização juntas. Relaciona-se à aceleração daqueles ramos e ao surgimento dos ramos novos, particularmente a indústria química, de refinação do petróleo, e do papel e celulose, acompanhando a arrancada do desenvolvimento urbano-industrial dos anos cinquenta. A multiplicação dos estabelecimentos metalúrgicos, da siderurgia, da indústria do cimento, e de papel e celulose intensifica os efeitos ambientais já acusados no momento anterior, ampliando esses efeitos a uma escala territorial mais ampla, com impacto maior no Sudeste em vista da sua concentração nessa região.

O terceiro momento corresponde ao tempo da quarta fase da industrialização, sem relação maior com ela todavia. Refere-se à política de deslocamento das indústrias de bens intermediários para a periferia do Sudeste do II PND (Plano Nacional de Desenvolvimento), fazendo a fronteira da mineração coincidir com a fronteira agrícola, que dá início à desconcentração industrial hoje em curso (MOREIRA, 2003). É o período dos pólos de grandes projetos. E é essa modelização da indústria de bens intermediários nos moldes dos grandes projetos o que torna este ramo o vilão do meio ambiente no Brasil. 
Um detalhamento da evolução da organização territorial das indústrias do ramo das indústrias de bens intermediários, tomado por referência o momento do II PND, esclarece os motivos que vieram a criar-lhe esta imagem.

O II PND (1975-1979) é um conjunto de políticas de desconcentração industrial, visando contornar os efeitos de três problemas: a crise do petróleo, que explode em 1973; a crise fiscal, que já então se anuncia; e a pressão ambiental interna, que cresce no Brasil a partir do incidente da indústria Borregaard, ocorrida nesse ano, em Porto Alegre (LESSA, 1998; e GREMAUD e PIRES, 1999b). O Plano prevê a implantação de pólos de indústrias de bens intermediários em Estados periféricos ao triângulo urbano-industrial de São Paulo-Rio de Janeiro-Belo Horizonte, em vista de atenuar pressões sindicais e ambientais aí ocorrentes. Uma sucessão de indústrias instalam-se assim em áreas de mineração do grande arco periférico que circunda a região core, aí formando diferentes pólos: o pólo químico-petroquímico do Triunfo-Canoas, nos arredores de Porto alegre; o pólo do nióbio e de fertilizantes, em Catalão, no sul de Goiás; o pólo mínero-vegetal-siderúrgico de Carajás, no sudeste do Pará; o pólo de potássicos, em Carmópolis, perto de Aracaju; o pólo petroquímico de Camaçari, nas cercanias de Salvador; o pólo petrolífero de Campos/norte fluminense, próximo ao Rio de Janeiro; o pólo de papel e celulose de Aracruz, ao norte de Vitória, no Espírito Santo; o pólo carboquímico de Crisciúma, ao sul de Florianópolis. São alguns exemplos do novo mapa industrial que então vai-se formando, com um grande círculo de pólos de bens intermediários localizado ao redor do Sudeste industrial, destinado a reduzir o grau de concentração dessa região, e indicando a intenção estratégica de implantar uma nova divisão territorial do trabalho industrial a partir da atuação desses pólos.

Se por um lado é bem sucedido o intento desse novo mapa, por outro lado tais pólos acabam, na prática, por nacionalizar o problema social e ambiental até então concentrado no Sudeste industrial.

Ocorre que o setor de bens intermediários é aquele que reúne as indústrias mais intensivas em recursos naturais e energia (TORRES, 1996). E cada pólo industrial de bens intermediários é o centro de uma rede de relações para trás e para frente, mobilizando, à montante, diferentes atividades de mineração, produtoras das matérias-primas do seu consumo, e, a jusante, diferentes lugares para onde manda os efeitos residuais de suas atividades produtivas. Cada ramo do bens intermediários irradia, assim, a degradação do meio ambiente para trás e para frente no âmbito da escala de espaço que estabelece. Veja-se o exemplo de uma indústria siderúrgica: localizemos as áreas de atividades de mineração do ferro, do carvão, materiais fundentes (calcário e dolomita) e energia que necessita para a produção do aço, e as de consumo para onde manda seus produtos, integrando em rede para trás e para frente de sua centralidade um naipe de diferentes lugares, e temos uma idéia do mapa do espaço do meio ambiente que só este complexo industrial traz consigo. Acrescente-se a este, o espaço industrial dos pólos dos ramos de químicos, petroquímicos, papel e celulose, e das várias metalurgias, com as redes de mineradoras e usinas que os alimentam em matérias-primas e energia, que se multiplicam após a 
década dos anos 70 ao longo do arco da periferia descrito, para apreendermos a escala nacional dos efeitos da estratégia de desconcentração industrial do II PND.

\section{BRASIL PRINCIPAIS ÁREAS DE ATIVIDADE MINERADORA}

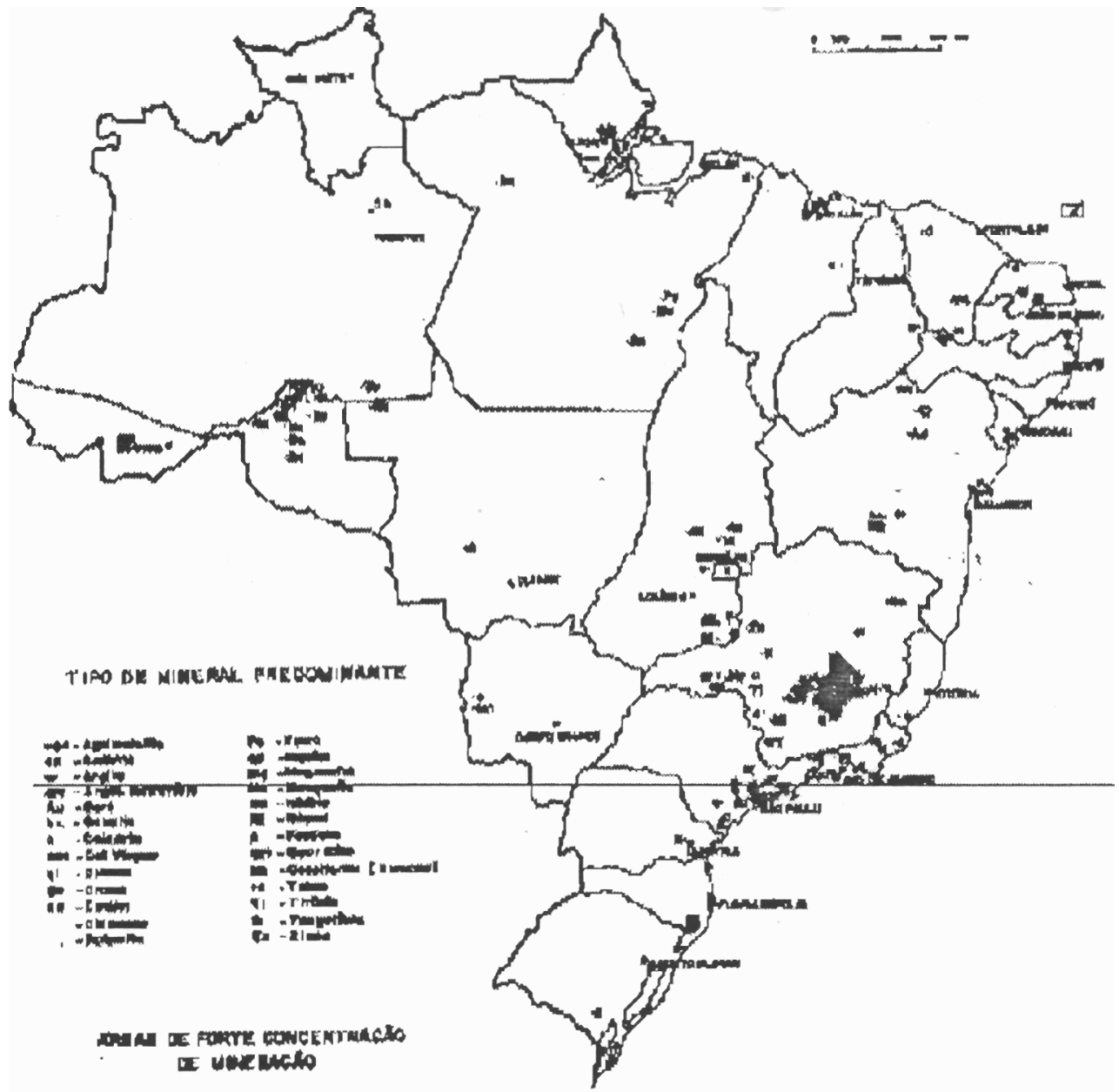

aris

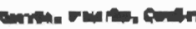

Mapa I - A dispersão dos pólos de mincração serviu de base para a estratégia da desconcentração do II PND, através da instalação dos pólos mínero-industriais de bens intermediários nos Estados do Rio Grande do Sul, Santa Catarina, Goiás, Pará, Sergipe, Bahia, Espírito Santo, num arco disposto ao longo da periferia do Sudeste industrial, levando os problemas socioambientais a espraiar-se nacionalmente a partir dos anos 70. Fonte: Diagnóstico Brasil: a octupaçāo do território e o meio ambiente. página 72. IBGE. 1990. 


\section{O modelo energético}

As usinas de energia hidrelétrica são um segundo caso desse mesmo capítulo. Usina e pólo de intermediários puxam um ao outro como políticas integradas do II PND, de modo que o mapa de efeitos socioambientais das usinas se soma ao mapa dos efeitos socioambientais dos pólos industriais de bens intermediários. Em verdade são aspectos de um mesmo ato.

A hidreletricidade é a forma por excelência de energia introduzida pela arrancada industrial no Brasil (LEITE, 1997). E a grande usina de barragem o seu padrão de espaço (VAINER e ARAÚJO, 1992). Também a usina hidrelétrica foi levada a deslocar-se para periferia pelo plano estratégico do II PND, de modo a vir a somar-se ao desenvolvimento dos pólos das indústrias de bens intermediários, ao mesmo tempo destinando-se a atrair os capitais para instalar-se e consolidar a fronteira agrícola nessas áreas. Lembrando a centralidade fabril dos pólos mínero-industriais, cada usina hidrelétrica é o centro de uma rede de transmissão de energia que transporta e dissemina a eletricidade sobre grandes áreas. A integração e entrecruzamento dessas redes leva a energia para todos os cantos do país, recobrindo todo o espaço brasileiro e extrapolando mesmo para os territórios vizinhos.

Implementada num país de rios de planaltos e de planícies, de regime tropical, de potencial de energia elevado mas ao mesmo tempo disperso ao longo do curso de grandes rios, a hidreletricidade se apoia desde o início na usina centrada nos grandes lagos de barragem. Um mal camuflado interesse do setor da indústria de construção civil, explica a opção por este modelo. Usando do seu poder junto aos governos, o interesse das construtoras, sobrepõe-se e vence os argumentos da academia e outros setores econômicos em prol de uma política de pequenas e médias usinas que cobriria de pequenas redes todo o espaço nacional. E, assim, no interesse do grande construtor, a rede das grandes usinas veio a constituir a viga mestra da própria política do ordenamento territorial no Brasil.

Isto explica o modelo seguido ao mesmo tempo pelo ramo de bens intermediários e pelo setor da energia no Brasil do II PND como forma geral de ordenamento territorial do espaço brasileiro (CASTRO, MOURA e MAIA, 178995).

E é sob a égide desse casamento entre política energética e interesse das construtoras que usinas hidreléticas e indústria de bens intermediárias vão somar-se, como as grandes vilãs do meio ambiente no plano da matriz espacial brasileira des anos recentes.

Sucede que a usina traz novas formas de problemas. Ao lado da devastação das matas e dos rios, as comunidades indígenas e camponesas são aqui as grandes vítimas. A grande represa atinge as áreas dos vales povoados por essas comunidades, inundando assentamentos humanos e matas galerias. Eixos históricos da formação e povoamento do território brasileiro, nesses vales é onde as comunidades indígenas e os novos povoadores se assentaram, uns e outros aí constituindo seus espaços de pertencimento (MOREIRA, 1990). Os grandes lagos de represamento, inundando es- 
tes vales, expulsam estas comunidades para outras áreas, onde vão ter que recomeçar suas formas de vida em novos espaços e ambientes, a partir do zero do pertencimento. Não raro, da experiência ambiental secularmente acumulada nas antigas áreas pouco se transfere para a ambiência nas novas, que então terá de ser criada. Dificuldade a que se acrescem os territórios de extensões em geral exíguas e sem a abundância de possibilidades que orientara a opção seletiva do habitat de antes.

Uma longa negociação tem então lugar entre as comunidades atingidas e o poder público, não raro o próprio autor da obra da represa e do ato da expulsão. Em consequência, a comunidade rapidamente definha e se desfaz, mercê da dificuldade de sobrevivência. Uma história que se repete onde se implante uma usina, formando um mapa de conflitos tão generalizado quanto o da degradação do ambiente promovido pela implantação dos grandes pólos da indústria de bens intermediários.

\section{O modelo dos transportes}

Base importante desse (des)ordenamento do espaço é o sistema de transportes, que a necessidade da interligação do centro com a periferia cada vez mais distante determina. O modelo é a rodovia (BARAT, 1978), a outra metade da política energética, vinculada a um consumo nacional crescente do petróleo, um ramo dos bens intermediários.

Historicamente o Brasil é o país das vias fluviais e das ferrovias. Longas trilhas de caminhos terrestres completam o mapa. Toda a ocupação do território é contada a partir desses caminhos formados primeiro pelos rios e trilhas terrestres e depois pelas ferrovias. Ao longo dessas vias se instalam as comunidades e as cidades, implantam-se as redes do comércio e expandem-se as manchas dos cultivos e do criatório. $\mathrm{O}$ advento da indústria altera os rumos dessa trajetória.

Dois interesses aqui se combinam. O histórico interesse das empresas construtoras. E o novel interesse das empresas do ramo da indústria automobilística. A construtora vai na frente e abre o caminho para o mercado dos automotivos. O Brasil está entrando na era do regime de acumulação com centro baseado no ramo automotivo e um outro explodem como agentes da passagem da matriz dos grandes espaços para a do espaço dos grandes projetos.

Longas fitas de cimento vão assim rasgando as áreas de campos, cerrados e florestas, abrindo uma multidão de caminhos vicinais e picadas para o coração desses biomas, num tipo de novo povoamento que no conjunto vai levar a uma devastação acelerada e em grande escala dessas formações vegetais, ordenando o novo espaço ao mesmo tempo que desordena o meio ambiente.

Um exemplo típico desse contraditório (re)ordenamento é o vasto espaço da Amazônia. Dominada secularmente por um sistema de circulação fluvial, de sentido sudoeste-nordeste na margem direita e noroeste-sudeste na margem esquerda do rio Amazonas, a Amazonia é invadida a partir dos anos 60 por um feixe de rodovias dé traçado transversal, que corta e intercepta no sentido leste-oeste a direção geral dos 
rios (VALVERDE e DIAS, 1967). Com o I PND (1970-1974), voltado para a modernização do campo, e o II PND (1975-1979), voltado para os grandes pólos míneroindustriais, estas rodovias, oriundas do Sudeste, se ampliam e atraem ondas de migrantes para as áreas dos grandes projetos agrícolas e pólos mínero-industriais, alterando por inteiro o quadro espaçoambiental da região. Áreas extensas de floresta são destruídas, rios inteiros se assoreiam, e as cidades, outrora pequenas, crescem desmesuradamente. Como que num ponto menor dessa invasão, multidões de garimpos se espalham como ondas de gafanhoto pela região amazônica, degradando-a generalizadamente.

\section{O modelo agrícola}

Mais é o modelo agrícola a argamassa desse processo.

A modernização do campo é o objeto do I PND, um plano de ocupação dos espaços do Centro-Oeste e da Amazônia por intermédio de grandes projetos de agropecuária implantandos a partir de 1970 (GREMAUD e PIRES, 1999a). Os grandes projetos de agropecuária vêm antes, e ao encontrarem, mais à frente, os grandes pólos mínero-industriais e energéticos do II PND, ganham sua maior arrancada. Assim, tal como nas telas das grandes paisagens, os pólos de bens intermediários, usinas hidrelétricas e longos eixos de rodovias, nacionalmente disseminados do triângulo São Paulo-Rio de Janeiro-Belo Horizonte rumo ao arco periférico das fronteiras, são os pontos e linhas de um arcabouço de espaço que no findar dos anos 70 as massas de tinta da modernização do campo vão ocupando e preenchendo.

$O$ vetor é aqui a agroindústria.

Devemos distinguir complexo agroindustrial de agroindústria (ARAÚJO, WEDEKIN E PINAZZA, s/d).

É da tradição da agricultura brasileira a agroindústria. Historicamente, podemos falar de três modalidades de agroindústria: a clássica, a expropriadora de renda e o complexo.

A agroindústria clássica vem do tempo da economia agromercantilexpor-tadora. Uma de suas características básicas é a presença da indústria de beneficiamento. Nem sempre a agroindústria aparece de forma clara. Às vezes, está comuflada por trás da indústria de beneficiamento. Entende-se por indústrias de beneficiamento todo um conjunto de atividades extra-agrícolas, que completam a produção da lavoura antes de seu produto ir para a exportação para o exterior. Seu grau de participação na agroexportação é variável, segundo o tipo de produto. Na lavoura cafeeira a indústria de beneficiamento limita-se ao trabalho de ressecamento do grão nos terrenos da propriedade cafeeira, que prepara o café, pela desidratação, para a torrefação, deixando-o em condições de ser exportado. Na cacaueira, tem um papel parecido, diferindo no detalhe de os bagos do cacau serem secados ao sol no teto móvel das habitações da fazenda. Na lavoura do fumo, tem a sofisticação do ressecamento nos varais, que ante- 
cipa a produção do fumo de rolo, forma já quase industrial com que o fumo é exportado. Esta sofisticação é igualmente nítida nos seringais, onde o látex é transformado em pelas, forma como a borracha natural é mandada para a exportação. Seja numa forma ou seja noutra, é uma característica da agroindústria a ligação orgânica da lavoura com a indústria, dentro ou próximo ao ambiente rural. $\mathrm{O}$ exemplo mais típico é o da agroindústria açucareira.

Um segundo tipo de agroindústria é o que surge com a instauração da acumulação capitalista de base industrial, mas em que o campo não modernizou-se ainda. Refere-se às indústrias relacionadas com a pequena produção agropecuária, mediante a qual a renda do pequeno produtor rural é expropriada e transferida para a acumulação industrial. Muitos foram os estudos dessa transferência, à exemplo da relação entre a pequena produção da uva e a indústria do vinho, no Rio Grande do Sul (SANTOS, 1978); os pequenos produtores do fumo e a indústria de cigarros, também no Rio Grande do Sul (ETGES, 1991); os pequenos produtores do chá, no vale do Ribeira em São Paulo (MULLER, 1980); os pequenos produtores do leite e as indústrias de laticínios, no Sudeste Brasileiro (FREDERICQ, 1982); e os pequenos e médios produtores do cacau e os intermediários da indústria do chocolate, no sul da Bahia (BAIARDI, 1984). São parte de um quadro de intensos conflitos que vão se acumulando no campo, e se alastram com a modernização (OLIVEIRA, 1991).

O complexo industrial é de natureza estrutural diferente. E está relacionado às transformações do campo que vêm com a modernização da agricultura. A modernização tem relação com a industrialização da agropecuária, superando as barreiras que separavam as atividades primárias e secundárias, com efeitos sobre a relação de ambos com o setor terciário. A modernização da agricultura é o propósito do I PND, de 1970, e dos Planos de Metas e Bases que o antecedem. Suas grandes linhas já podem ser encontradas no Estatuto da Terra, de 1964, onde talvez o próprio auge do modelo industrial que tudo informa comece. Sabe-se que a modernização do campo dá origem a uma nova fase da industrialização substitutiva de importações no Brasil. A última. Muito já foi escrito sobre o processo. Apontemos aqui os elementos que mais nos interessam. Primeiramente, a indústria de beneficiamento perde seu elo orgânico com a fazenda para ganhar a autonomia de uma atividade especializada. Por outro lado, atividades do setor terciário, como a armazenagem, silagem e transportes, incorporam-se estruturalmente à agroindústria. Bem como as atividades de pesquisa, voltadas à diversificação e recriação das sementes. Tudo isto vai significar uma nova divisão territorial do trabalho, que transforma a antiga agroindústria numa estrutura orgânica de escala territorial de extensão mais ampla e complexa.

É dessa natureza a agroindústria criada a partir da modernização da agricultura. Modernização significa industrialização do campo, um casamento que leva agropecuária e indústria a se fundirem numa mesma atividade econômica: de um lado, a demanda da modernização do campo suscita o surgimento de um setor de 
insumos da indústria para o campo, nascendo o ramo da indústria para a agricultura, a indústria de máquinas, fertilizantes e defensivos agrícolas, de outro, a incorporação desses insumos pela agropecuária leva ao nascimento de uma agricultura industrial nas áreas rurais brasileiras (MULLER, 1989; e MAZZALI, 2000). Fusão que junta tudo num só mundo.

A criação de uma agricultura industrial no campo e um ramo da indústria para a agricultura no sistema da indústria é o quadro de referência do salto que vai transformar a agroindústria no complexo agroindustrial, criando a última fase da industrialização substitutiva de importações, que completa o quadro de auto-sustentabilidade do parque industrial no Brasil. Todo um sistema financeiro apoiado na intervenção e subsídios do Estado é montado para isto.

A sojicultura é o melhor exemplo. Aqui a complexidade já se dá dentro da propria agroindústria, hoje formada pela cadeia soja-grão-carne, uma tentativa de controlar o efeito ambiental do cultivo único da soja e problemas de custo, ao mesmo tempo. O fenômeno repete-se nas áreas do cítrico, do álcool-açúcar, do laticínio (MAZZALI, 2000).

Territorialmente, a modernização do campo tem o significado de uma expansão da agricultura paulista para as áreas agrícolas da periferia, do Sul, do Centro-Oeste e do oeste de Minas Gerais, num arco de extensão Sul-Norte, que passa pelas áreas mais próximas do Centro-Oeste. Ao longo das áreas desse arco, a.agricultura se mecaniza, aplicam-se fertilizantes e difunde-se a aplicação dos defensivos agrícolas. Tudo isto em escala muito ampla. $O$ mesmo sucede com a pecuária.

A agricultura de mercado então avança pelo campo, eliminando ou ilhando em pequenos espaços a produção familiar camponesa, que, em certa medida e no quadro dos seus limites, vê-se obrigada também a modificar-se. A grande propriedade se transforma numa empresa rural, organizando-se e seguindo as normas contábeis de toda empresa moderna capitalista. E a pequena desaparece ou se capitaliza.

A agroindústria esta relacionada com o chamado grande produto, o produto destinado ao grande mercado, sinônimo de mercado externo, mesmo quando praticado em pequenas e médias propriedades. Geralmente, entretanto, relaciona-se à grande propriedade e à monocultura, fontes históricas da predação ambiental no Brasil. A pequena produção policultora fazendo um contraste com ela.

Chama-se policultura ao tipo de produção rural baseada na combinação de vários produtos no mesmo estabelecimento agrícola. Objeto de pejoração, é chamada de agricultura de roça e promíscua, pela sua aparente falta de racionalidade econômica. Entretanto, há diferentes tipos de policultura no campo brasileiro e todas estas formas vêm se tornando ultimamente objeto de pesquisas dado sua maior proximidade com o tema da biodiversidade. Há desde a policultura do campesinato brasileiro, menos biodiversa, até a policultura indígena, se podemos considerá-la assim, caso típico de ampla biodiversidade. Seja como for, é exatamente seu policultivo e vínculo com a pequena propriedade que a torna um tipo de agricultura pouco predatória do meio ambiente, mesmo descontada a prática da 
queimada, em que classicamente se apoia como recurso técnico. Além de que sua aparente falta de racionalidade é apenas aparente, dado que por trás da simultaneidade dos múltiplos cultivos está a estratégia do policultor de driblar as adversidades da intempérie, já que seja qual for o comportamento da natureza sempre haverá dentre os cultivos um que sobreviva à chuva ou à seca inesperadas, e assim este pequeno produtor sempre terá algum alimento de que se prover. Há uma racionalidade camponesa, pois, e então diferente da racionalidade capitalista, determinada pela lógica e regras da economia de mercado. É, por sinal, esta pequena policultura a responsável por mais da metade da produção de alimentos que chega ao mercado para o abastecimento da sociedade brasileira.

Historicamente o modelo agrícola brasileiro é este binômio grande e pequena produção, em geral estruturado como um binômio latifúndio-minifúndio, o latifundio coincidindo com o grande produto de mercado, a monocultura e a grande propriedade e o minifúndio com o pequeno produto alimentício, a policultura e a pequena propriedade (mais comumente o pequeno estabelecimento), cada qual distinguindose por uma função dentro de um desenvolvimento desigual e combinado (MOREIRA, 1990). A modernização do campo atinge em cheio esta estrutura binominal, alterando o modelo agrícola no tocante à presença minifundiária. Grande parte dos minifundiários, tanto aqueles relacionados à terra mas sem vínculos formais de propriedade, do tipo parceiros, condiceiros, foreiros, quanto pequenos proprietários, em particular das áreas rurais da região Sudeste-Sul, vão sendo expulsos do campo, frente ao avanço e modernização da grande empresa rural. Levas de camponeses tornam-se bóias-frias e sem-terras, expulsos pela mecanização e expansão dos grandes cultivos como a soja. As relações agrárias se transformam, multiplicando em simultâneo no campo os conflitos ambientais e os conflitos pela terra, não raro interrelacionados e na mesma área.

O efeito da modernização é assim sócioambiental e devastador. A combinação de crédito agrícola facilitado e uso intensivo de insumos industriais leva o duplo plantação-bovinos a expandir-se espaço brasileiro a dentro. A grande produção avança, dissolvendo o binômio onde se industrializa, a caminho da fronteira agrícola amazônica.

A expansão da monocultura da soja dá o exemplo clássico. Vinda do sul, junto ao migrante gaúcho, a soja se espalha pelo topo plano das chapadas do planalto central. A mecanização intensiva expõe os microorganismos à insolação e o solo à erosão das chuvas e dos ventos. $O$ combate às pragas e ervas daninhas, conceito advindo da destruição e desequilíbrio da cadeia ecossistêmica, envenena os solos e as águas dos rios. Uma destruição generalizada da cobertura vegetal dos cerrados e a seguir da floresta amazônica e o consequente assoreamento em larga escala dos rios completa o quadro (NETO, 1982).

Um outro fio é a expansão do criatório bovino à base das pastagens. Aqui são as queimadas, usadas para renovação rápida e barata do pasto, o problema. 


\section{A MARCHA DA MODERNIZAÇÃO DO CAMPO NO BRASIL}

\section{EMPRESAS DE AVIAÇÃO AGRÍCOLA NO BRASIL - 1975}

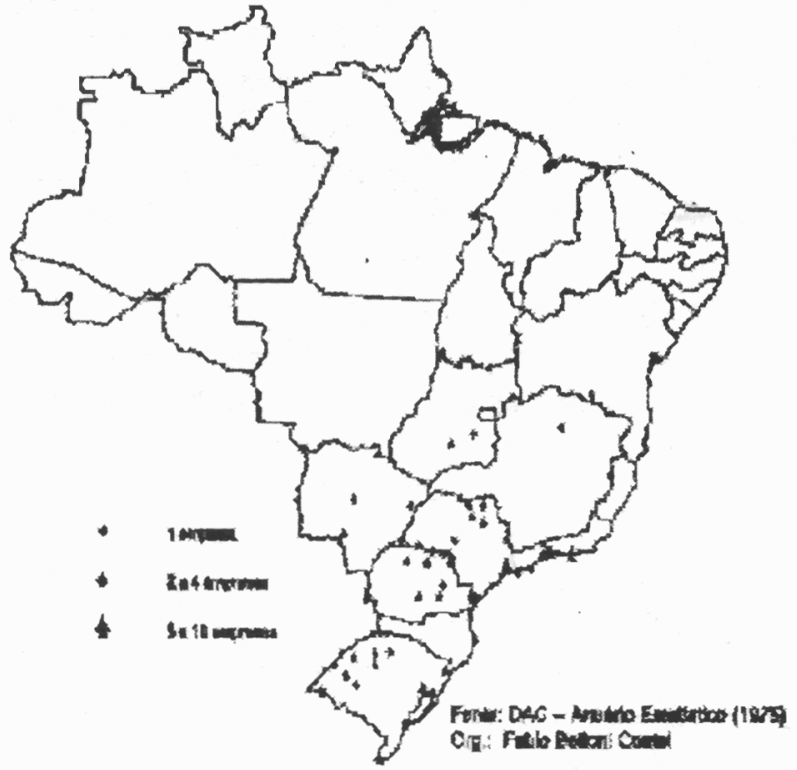

EMPRESAS DE AVIAÇÃO AGRICOLA NO BRASIL - 1995

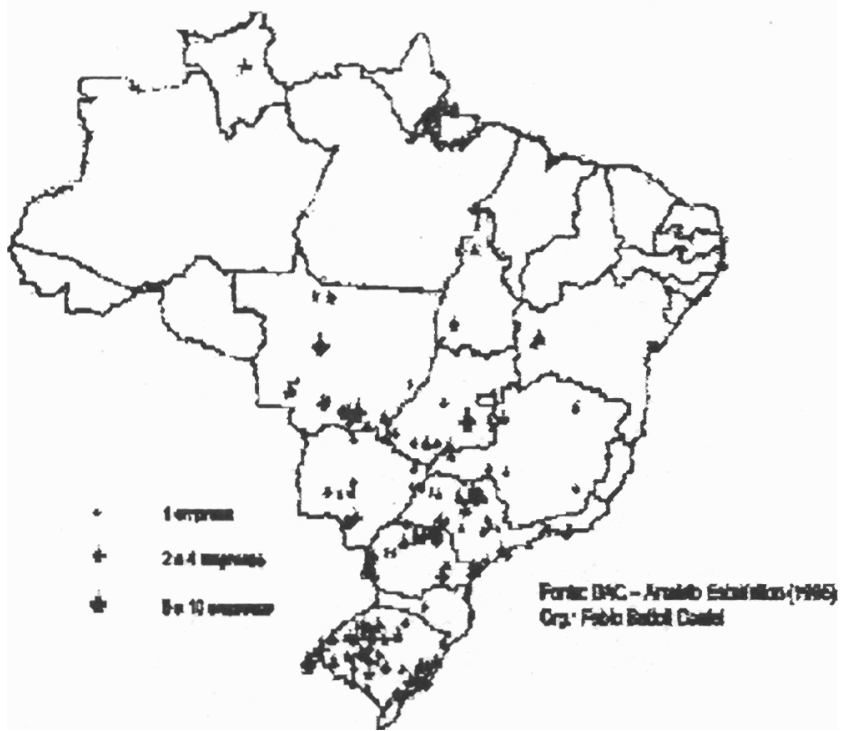

Mapa 2 - A comparação dos mapas mostra a marcha da modernização da agropecuária rumo ao Centro-Oeste e à Amazônia, avançando sobre o cerrado e a floresta amazônica. Fonte: SANTOS e SILVEIRA: O Brasil: território e sociedade no inicio do século XXI. 2001 (adaptado). 
Em pouco tempo este é o arranjo que se implanta no espaço brasileiro, de sul a norte e de leste a oeste, desde o Rio Grande do Sul à Amazônia e desde o oeste da Bahia às portas do pantanal matogrossense, estimulado pela abundância de energia, facilidade dos transportes e acessibilidade aos insumos industriais em grande escala.

Entretanto, esse quadro agrícola baseado no uso mono do solo (ou soja ou gado) é o modelo histórico da organização do espaço agrário brasileiro (MOREIRA, 1981). Costurado na forma dos macro-espaços desde o tempo da Colônia, em cada ciclo econômico do passado vê-se este modelo ocupando os térritórios, com os mesmos efeitos ambientais vistos agora. Capistrano dá-nos a medida da destruição da Mata Atlântica pela monocultura da cana na Zona da Mata Nordestina. Cada caldeira do antigo engenho consumia 6 carros de boi de lenha por dia. Um bom engenho possuia 6 caldeiras. Pode-se avaliar por estes dados o quão foi devastador o poder da monocultura. Sabemos que foi o mesmo o efeito da monocultura do café sobre a Mata Atlântica na região Sudeste.

O impacto ambiental da sojicultura tem entretanto proporções maiores que a das monoculturas da cana e do café, juntas, seja pela extensão de área que abranje e seja por ser uma lavoura intensiva em tecnologia. Acrescente-se o consumo da água através de uma tecnologia de irrigação que retira a água a grandes profundidades do subsolo justamente das chapadas do planalto central, secando a "caixa d’água" que alimenta o curso dos rios da bacia do Amazonas, para o norte, e do.Paraná-Paraguai, para o sul, numa escala de abrangência de mais da metade do território brasileiro.

\section{O modelo urbano}

A cidade está no meio desse quadro de degradação do meio ambiente relacionado ao espaço geográfico criado pelo modelo industrial no Brasil. E assim, incorpora sinteticamente todos seus efeitos, ao tempo que enfrenta problemas próprios.

Exprimindo a um só tempo a estrutura oligopólica e a modernização gerada pela industrialização do campo, as cidades brasileiras se metropolitanizam rapidamente, mais de oito delas ultrapassando a cota de um milhão de habitantes em pouco tempo. A especulação imobiliária que então tem lugar, faz dos espaços urbanos lugar-sinônimos de espaço desordenado e degradado ambientalmente, instaurando o caos urbano ( KOWARICK, 1979).

Nas cidades industriais, em particular, a poluição industrial se soma aos efeitos ambientais do urbanismo. Assim, ao lançamento de resíduos gasosos na atmosfera pela indústria siderúrgica, como em Volta Redonda (CSN) e Vila Parisi (COSIPA), relacionam-se os inúmeros problemas de saúde, a exemplo da leucopenia, doença relacionada ao lançamento do benzeno, subproduto da coqueria, no ar, assim como resíduos sólidos nas águas dos córregos e rios. Por outro lado, ao crescimento desordenado de cidades de topografia movimentada, como o Rio, de onde a especulação com os melhores terrenos empurra a população para as encostas dos morros e margens dos 
cursos d'água da cidade, dando origem às favelas, relacionam-se as catástrofes das épocas de chuvas fortes, que desmancham e instabilizam as encostas dos morros e produzem o transbordamento dos rios, desalojando e vitimando com mortes seus habitantes. Grandes acúmulos de lixo, amontoados e sem tratamento em áreas da cidade, completam um quadro de precariedade de saneamento básico que faz da água e do esgoto uma fonte de problemas ambientais urbanos. Somam-se a isto as "ilhas de calor", que alteram totalmente o clima das cidades (LOMBARDO, 1985).

\section{o Modelo industrial, o modelo espacial e o meio ambiente}

Há, pois, uma clara relação entre o modo como a sociedade brasileira foi se assentando territorialmente e os problemas de meio ambiente tal como foram ocorrendo. Num claro exemplo de didatismo, a história espacial da sociedade brasileira é a história dos problemas ambientais do país.

Três ordens de consideração devem aqui ser feitas. A primeira refere-se ao sujeito da construção do espaço. A segunda, à relação entre espaço e ambiente na análise ambiental no âmbito da geografia. A terceira, à pesquisa da relação histórica entre formação sócio-espacial e problemas sócioambientais no Brasil.

A linha de ligação dos setores com o amplo mapa de degradação do meio ambiente que vimos, é empiricamente o modo de desenvolvimento do setor de bens intermediários. Via relação que têm com o interesse da indústria de construção civil, que faz o setor como um todo materializar-se no pivo da política antisocioambiental dos grandes projetos. Assim, a obra da usina, da rodovia ou urbana, formulada como um bem social, acaba se convertendo num grande pólo de degradação do meio ambiente.

Agente de construção de um espaço comandado por um regime de acumulação monopolista que vai buscar no longínquo as margens de valor que acumula em grandes lucros, a empresa construtora é todavia a ponta do iceberg de um campo de interesses que é estruturalmente mais amplo.

É em função desse amplo campo de interesses que o grande arco de entrelaçamento energia-transportes-cidades-indústrias de bens intermediários, seguindo a lógica que preside o modo de desenvolvimento industrial, responde pela constituição de um modelo de organização do espaço que é o princípio gerador de toda a desarrumação sócioambiental presente na sociedade brasileira.

Se a indústria de bens intermediários é filha dos grandes projetos de construção, de usinas, rodovias ou cidades, e a política dos grandes projetos é filha da performance e constante desenvolvimento da indústria de bens intermediários, isto exprime o peso da presença das empresas de construção na formulação do modelo espacial, por força do seu poder de determinação do modelo da política energética, dos transportes e do espaço urbano, via seu casamento com a indústria de bens intermediários (particularmente via os ramos do cimento e da indústria de materias de construção). Afinal, do aço ao cimento, a implantação de uma grande usina, de uma cidade ou 
uma rodovia significa um consumo em grande escala de bens industriais intermediários. Vimos que isto explica a opção por grandes projetos, seja para a usina, seja para a rodovia ou o modelo de cidade. E a participação permanente que setor de bens intermediários vem a ter ao longo da implementação da moderna indústria no Brasil. Mas o poder e o benefício do modelo é mais amplo e distribuído pelos próprios detentores do domínio dos setores, entre eles o Estado, de que a indústria de construção é a ponta de lança.

Pólos industriais, usinas, cidades e grandes paisagens agropecuárias são partes integrantes de uma mesma estratégia de organização de espaço: a da acumulação conjunta do grande capital, em que se incluem as construtoras.

E é exprimindo esse quadro comum de interesses, que, com vista a organizar um arranjo de espaço que ordene a acumulação capitalista no Brasil, em todo o país, pólos e usinas, combinados, ordenam a acumulação e degradam o meio ambiente, numa rede de interesses entrecruzados, que ainda não foi nacionalmente avaliada. Não por mera coincidência, o mapa da acumulação e o das degradações é o mesmo.

De fato, os setores seguem e se interligam na mesma lógica que preside modelo de espaço e modelo de indústria. Por isso, as usinas hidrelétricas estão combinadas aos grandes projetos de agropecuária. Do mesmo modo que formam o centro da política de fomento da fronteira mínero-industrial. Servem de elo entre uma fronteira e outra. Idem as rodovias, que enfeixam usinas, pólos mínero-industriais, grande manchas agrícolas e metrópoles na teia de sua rede. Servindo a isto tudo, o ramo da indústria de bens intermediários. Os modelos setoriais assim se fecham, convergentes, numa lógica que claramente é a mesma.

Há que qualificar assim os sujeitos do meio ambiente no espaço brasileiro.

O modelo de organização do espaço todavia nem sempre é considerado nas análises dos problemas do meio ambiente. Menos corrente ainda é a consideração do modelo industrial, muito embora tenha se escolhido a indústria como vilão do meio ambiente.

E nem se pode dizer que a relação modelo de espaço e problemas de meio ambiente é recente. Já nos referimos a este tema no início deste texto.

Há que se resolver então este problema teórico da relação espaço- meio ambiente.

Por fim, a ruptura da justaposição entre fazendas de cultivos e a faixa florestal atlântica, ao longo da costa, e fazendas de gado e vegetação campestre, no interior, própria do assentamento humano no correr dos séculos de Colônia, pode ajudar a esclarecer esta relação (MOREIRA, 1990). A devastação da cobertura florestal da mata atlântica não encontrava paralelo na quase inalteração do quadro vegetal das áreas de campos, cerrados e caatingas, nas quais viceja e se espalha o criatório. Nem mesmo o alto consumo de lenha como forma de energia, comum a todo o espaço colonial, ou os resíduos químicos das indústrias de beneficiamento, igualmente ubíquos naquele espaço, produziram um suficiente alerta quanto aos impactos ambientais das formas de uso da terra e ocupação do território em ocorrência. No entanto, são muitos os relatos que dão conta das alterações do meio ambiente em todos os tempos 
do passado. Fruto de uma quebra histórica entre a forma de gestão ambiental praticada pelas comunidades indígenas e a forma de gestão que os colonizadores aqui vão introduzir (GONÇALVES, 2000).

Há, por exemplo, inúmeras referências nas obras dos naturalistas e viajantes às paisagens e suas alterações nos espaços do Brasil dos séculos passados. Ou nas obras clássicas de análise da evolução brasileira, à exemplo de Aires de Casal, Varnhagen e Capistrano de Abreu. Sem falar dos pintores, como Rugendas e Debret. Fontes de resgate da relação modo de formação do território e modo de desarrumação do meio ambiente, que não foram utilizadas porque a pesquisa ambiental no Brasil pouco percebeu acerca da relação, em si óbvia, entre espaço e meio ambiente.

Foi só quando a lavoura se esparramou para as áreas de formação aberta, disputando-a com o criatório, realizando uma radical substituição da cobertura original e quebrando com violência a cadeia do ecossistema, com impacto evidente sobre o meio ambiente, que os registros do efeito começam a se multiplicar. Não porque só então o uso mono existisse como norma e cobrasse seus efeitos de destruição. Mas porque a vida urbana já começava a prosperar e a atividade intelectual que the é própria passava a tematizar questões como a do meio ambiente. Não foi porém o bastante.

Ainda agora, quando já estamos no nosso tempo, e dado a voracidade industrial, face o modo modelar como se deu e modelizou cada setor que adicionou à sua estrutura, como o ramo dos bens intermediários, da energia, dos transportes, agrícola e urbano, o problema ambiental, então, como vimos, ganhou escala e generalizou-se pelos registros dos relatórios de governo, textos dos intelectuais e coberturas jornalísticas, ainda assim essa relação óbvia entre modo de organização do espaço e modo de eclosão dos problemas de meio ambiente não deu azo a uma pesquisa contundente.

Nem mesmo o geógrafo, profissional da relação homem-meio desde quando se entende, e obrigado, por formação, a enfocar o meio ambiente em termos de modelo de organização de espaço, e assim do território e seus domínios de arranjo, realizou este empreendimento até agora quanto ao espaço brasileiro.

Há pois que também pesquisar esta relação histórico-concreta.

\section{INDÚSTRIA E MEIO AMBIENTE NO ESPAÇO BRASILEIRO}

Sumário: Há uma relação entre a eclosão dos problemas e o modelo de desenvolvimento industrial no espaço brasileiro. O modelo do desenvolvimento industrial é a origem dos problemas ambientais. Este texto é uma análise dessa relação entre indústria e meio ambiente no âmbito global do espaço brasileiro.

Palavras-chave: industrialização, matriz espacial e meio ambiente

\section{INDUSTRY AND ENVIRONMENT IN BRAZILIAN SPACE}

Abstract: There is a intimate relation between environmental problems and developmente industrial model in brazilian space organization. Model of industrialization is the origin of environmental problems in Brazil. This text analyse the relationship between industry and environment in global brazilian geographic space.

Keywords: industrialization, spacial matrix, environment 


\section{BIBLIOGRAFIA}

ARAÚJO, Ney B., WEDEKIN, Ivan, e PINAZZA, Luiz Antonio. s/d. Complexo Agroindustrial - o "agrobusines" brasileiro. São Paulo: Suma Econômica/ Agroceres

BAIARDI, Amilcar. 1984. Subordinação do Trabalho ao Capital na Lavoura Cacaueira da Bahia. São Paulo: Editora Hucitec

BARAT, Josej. 1978. A Evolução os Transportes no Brasil. Rio de Janeiro: IBGE/ IPEA

BAUDRILLARD, Jean. s/d. A Economia Política dos Signos. Lisboa: Martins Fontes

CASTRO, Antônio de B. 1977. A Industrialização Descentralizada no Brasil, in 7 Ensaios sobre a Economia Brasileira. Rio de Janeiro: Forense Universitária.

CASTRO, Edna, MOURA, Edite A. F., e MAIA, M. L. Sá. 1995. Indıstrialização e Grandes Projetos. Belém: UFPA/NAEA.

ETGES, Virginia Elisabeta. 1981. Sujeição e Resistência: os camponeses gaúchos e $a$ indústria do fumo. Santa Cruz do Sul: Livraria e Editora da FISC.

FREDERICQ, Antoinette. 1981. A "Babá" dos Brasileiros: uma multinacional no setor leiteiro. in Agricultura, Cooperativas e Multinacionais. CORADINI, Luiz Odacir (org). Rio de Janeiro: Zahar Editores

GEIGER, P. P. (Coord).1963. Estudos para a Geografia da Indústria no Brasil. in Revista Brasileira de Geografia, 25(2). Rio de Janeiro: IBGE

GEORGE, Pierre. s/d. A Ação Humana. São Paulo: Difel

GONÇALVES, C. W. Porto. . . (Des)Caminhos do Meio Ambiente. São Paulo: Editora Contexto

GREMAUD, A. P. e PIRES, J. M. 1999a. "Metas e Bases" e I Plano Nacional de Desenvolvimento - I PND (1970-1974). in Planejamento no Brasil II, KON, Anita (Org). São Paulo: Editora Perspectiva.

1999b. II Plano Nacional de Desenvolvimento II PND (1975-1979). in Planejamento no Brasil II, KON, Anita (org). São Paulo: Editora Perspectiva.

KOWARICK, Lúcio. 1979. A Lógica da Desordem. in A Espoliação Urbana. Rio de Janeiro: Editora Paz e Terra

LEITE, Antonio Dias. 1997. A Energia do Brasil. Rio de Janeiro: Editora Nova Fronteira

LESSA, Carlos. 1998. A Estratégia de Desenvolvimento - 1974-1976. Sonho e Fracasso. Campinas: UNICAMP

LOMBARDO, Magda Adelaide. 1985. Ilha de calor nas Metrópoles. O caso de São Paulo. Hucitec: São Paulo.

MARX, Karl. . A Ideologia Alemã (Feuerbach). São Paulo: Editora Hucitec

MAZZILI, Leonel. 2000. O Processo Recente de Reorganaização Industrial: do complexo à organização "em rede". São Paulo: Editora UNESP 
MOREIRA, Ruy. 2003. Os Novos Padrões do Espaço Industrial Brasileiro. in 2003. Os Quatro Modelos de Espaço-Tempo e A Reestruturação Espacial Brasileira. in

2001. As Categorias Espaciais da Construção Geográfica das Sociedades. in GEOgraphia, ano 3, no. 5. Niterói: PPGEO-UFF

1997. Da Região à Rede e ao Lugar (A nova realidade e o novo olhar geográfico sobre o mundo). in Revista Ciência Geográfica, ano 2, no. 6. Bauru: AGB-Bauru

1993. O Círculo e a Espiral. A Crise do Paradigma Moderno. Rio de Janeiro: Cooautor/Obra Aberta.

1991. O Conceito de Natureza na Geografia Física. in Caderno Prudentino de Geografia, no. 13, junho. Presidente Prudente: AGB-PP

1990. A Formação do Espaço Agrário no Brasil. Coleção Tudo é História no. 132. São Paulo: Editora Brasiliense

1982. Geografia, Ecologia, Ideologia: a "totalidade homem-meio hoje" (espaço e processo do trabalho). in Geografia: Teoria e Crítica-O saber posto em questão. Ruy Moreira (org). Rio de Janeiro: Editora Vozes

1981. "Plantation" e Formação Espacial: as raízes do Estado-Nação no Brasil. in Contribuição ao Estudo da Geografia Agrária. Rio de Janeiro: Departamento de Geografia/PUC-RJ

MULLER, Geraldo. 1989. Complexo Agroindustrial e Modernização Agrária. São Păulo: Editora Hucitec/Editora da PUC-SP

NETO, Francisco Grazziano. 1982. Questão Agrária e Ecologia. Crítica da moderna agricultura. São Paulo: Editora Brasiliense

OLIVEIRA, Ariovaldo Umbelino. 1991. A Agricultura Camponesa no Brasil. São Paulo: Editora Contexto.

OLIVEIRA, Francisco. Mudança na divisão inter-regional do trabalho no Brasil. in A Economia da Dependência Imperfeita. Rio de Janeiro: Graal Editora

SANTOS, Milton e SILVEIRA, Maria Laura. 2001. O Brasil: território e sociedade no início do séxulo XXI. Rio de Janeiro: Editora Record

SANTOS, José Vicente Tavares. 1978. Colonos do Vinho. São Paulo: Editora Hucitec TORRES, Haroldo da Gama. 1996. Indústrias sujas e intensivas em recursos naturais: importância crescente no cenário industrial brasileiro. in População, Meio Ambiente e desenvolvimento. George Martine (org). Campinas: Editora da UNICAMP

VALVERDE, Orlando e DIAS, Catharino V. 1967. A Rodovia Belém-Brasília. Rio de Janeiro: IBGE

VAINER, Carlos B. e ARAÚJO, F. G. B. 1992. Grandes Projetos Hidrelétricos e Desenvolvimento Regional. Rio de Janeiro: IPPUR/UFRJ/CEDI

THOMPSON, J. P. 1998. Tempo, Disciplina de Trabalho e o Capitalismo Industrial. in Costumes em Comum: estudos sobre a cultura popular tradicional. São Paulo: Companhia das Letras. 